\title{
The Fracture of Plasma-Treated Polyurethane Surface under Fatigue Loading
}

\author{
Ilya A. Morozov 1,2,*iD, Alexander S. Mamaev ${ }^{3}$, Mikhail V. Bannikov ${ }^{1}$, Anton Yu. Beliaev ${ }^{1}$ \\ and Irina V. Osorgina ${ }^{2}$ \\ 1 Institute of continuous media mechanics, Ural Branch of Russian Academy of Sciences, \\ Academika Koroleva st. 1, 614013 Perm, Russia; mbannikov@icmm.ru (M.V.B.); belyaev@icmm.ru (A.Y.B.) \\ 2 Department of Mechanics of Continuous Media and Computational Technologies, Perm State University, \\ Bukireva st. 15, 614990 Perm, Russia; osorgina@psu.ru \\ 3 Institute of Electrophysics, Ural Branch of Russian Academy of Sciences, Amundsen st. 106, \\ 620016 Ekaterinburg, Russia; alexander.sm@mail.ru \\ * Correspondence: ilya.morozov@gmail.com; Tel.: +7-342-237-8315
}

Received: 6 January 2018; Accepted: 11 February 2018; Published: 14 February 2018

\begin{abstract}
Plasma treatment of soft polymers is a promising technique to improve biomedical properties of the materials. The response to the deformation of such materials is not yet clear. Soft elastic polyurethane treated with plasma immersion ion implantation is subjected to fatigue uniaxial loading. The influence of the strain amplitude and the plasma treatment regime on damage character is discussed. Surface defects are studied in unloaded and stretched states of the material. As a result of fatigue loading, transverse cracks (with closed overlapping edges as well as with open edges deeply propagating into the polymer) and longitudinal folds which are break and bend inward, appear on the surface. Hard edges of cracks cut the soft polymer which is squeezed from the bulk to the surface. The observed damages are related to the high stiffness of the modified surface and its transition to the polymer substrate.
\end{abstract}

Keywords: plasma treatment; fatigue loading; fracture; polyurethane; surface morphology

\section{Introduction}

Surface modification by plasma methods improves various material properties: corrosion and wear resistance [1], hardness, adhesion characteristics. Metals, ceramics and stiff polymers are widely used materials for such applications. Considerable applied studies are focused on the plasma modification of products with complex three-dimensional shape [2] and/or small size. One of the most important areas of research is the effect of plasma treatment on the biomedical characteristics of materials (antibacterial properties, thrombogenesis, biocompatibility, friction, drug transport) [3].

Depending on the composition and manufacture conditions, the mechanical properties of the polyurethane are varied in a wide range: from soft elastomers to hard plastics. Polyurethanes are suitable for creating catheters, cardio- and breast-implants, interphalangeal endoprostheses, etc.

Plasma treatment of the polymers changes the relief, physico-chemical and mechanical properties of the surface. In particular, surface energy, i.e., wettability, changes significantly, which affects the interaction with biological objects [4]: an increase of surface energy decreases the number of platelets adsorbed onto the surface [5,6]. Certain treatment regimens allow creating discontinuous cluster-like carbon coatings [7] with selective adsorption of blood proteins. As a result of ion-plasma implantation free radicals appear in the treated surface layer [8], some authors suppose that it makes the surface more favorable for the proteins [9]. The usage of silver [10] or copper [11] ions improves the antimicrobial properties. The plasma is used control of the drug release rate [12] and affects hardness [13], adhesion and friction coefficient [14] of the treated polymers. 
Treatment of soft polymer leads to the formation of a pronounced wrinkled texture on the surface [15], the peculiarities of surface texture affect the antibacterial properties of the coating [16,17]. The wrinkling phenomenon is related with the loss of stability of the hard layer on the soft substrate due to thermal-induced deformation [18].

In all the known works devoted to plasma treatment of polymers, the materials are tested and studied in a relatively immobile state, even in the case of implantation of samples into the body. The real conditions for exploitation of elastomeric implants imply the presence of large cyclic deformations. The stiffness of the plasma-modified layer could be many times greater than the elastic modulus of the soft polymer "substrate" [19]. As a result, even simple uniaxial deformations fracture the modified surface $[17,20]$ and could damage of implant and body tissues.

This work is devoted to the study of the effect of fatigue uniaxial deformation on the surface of soft elastic polyurethane treated with plasma immersion ion implantation. The formation of cracks (including bulging of the polymer), folds and the areas with an exfoliated surface layer are investigated. The results depend both on the energy and fluence of treatment as well as the strain amplitude.

\section{Materials and Methods}

\subsection{Manufacturing of Materials}

A polyurethane composition (PU) was investigated. The material was prepared from commercial ready to use ingredients according to datasheet. Urethane prepolymer (NCO/OH ratio is 100:43.3, $\mathrm{Mw}=2300$ ) based on a simple polyether (by Mitsubishi Chemical Corporation, Tokyo, Japan) and toluene diisocyanate (by Bayer International C.A., Leverkusen, Germany) was heated to $50{ }^{\circ} \mathrm{C}$ and vacuumed for $7 \mathrm{~min}$. Then the remaining components (per $100 \mathrm{wt} . \%$ parts of prepolymer): $9.6 \mathrm{wt} . \%$ parts of hardener MOKA (4.4'-Methylenebis (2-Chloroaniline)) and $34.2 \mathrm{wt} . \%$ parts of plasticizer polyfurite (polyoxytetramethylene glycol) were heated to $60^{\circ} \mathrm{C}$ and mixed with the polymer for $3 \mathrm{~min}$. The mixture was again vacuumed at $50{ }^{\circ} \mathrm{C}$ for $5 \mathrm{~min}$. The composition was press-molded and cured in the vacuum oven at $100{ }^{\circ} \mathrm{C}$ for $18 \mathrm{~h}$. The thickness of the plates was $2 \mathrm{~mm}$. Dogbone samples were cut from the plates (working dimensions $25 \times 4 \mathrm{~mm}^{2}$ ) for the mechanical tests.

\subsection{Plasma Treatment}

The samples were treated from both sides with plasma immersion implantation of $\mathrm{N}_{2}{ }^{+}$ions. A source of electrons with a plasma cathode based on a glowing discharge was used to generate plasma in the vacuum chamber [21]. The chamber was filled with nitrogen at a rate of $20 \mathrm{~mL} / \mathrm{min}$ and the working gas pressure was $0.2 \mathrm{~Pa}$. The electrons were accelerated up to the energy of $10-20 \mathrm{eV}$ in the region of the plasma cathode grid. An electrically isolated sample holder cooling by running water to a room temperature was located inside the chamber at a distance of $150 \mathrm{~mm}$ from the grid of the electron source. The samples were placed inside the holder and covered with a metal mesh with a mesh space of $10 \mathrm{~mm}$. A constant negative bias voltage of 1 or $3 \mathrm{kV}$ was applied to the holder. Plasma ions were generated by the electron beam and accelerated in the layer of a space charge region created near the mesh. The treatment modes were determined from the condition that the average intensity of the ion flow to the sample surface does not exceed $15 \mathrm{~mW} / \mathrm{cm}^{2}$. This allowed maintaining the sample at a temperature $\leq 80^{\circ} \mathrm{C}$. Three different treatment modes were applied: energy $1 \mathrm{keV}$ (fluence $2 \times 10^{16}$ or $2 \times 10^{17} \mathrm{ion} / \mathrm{cm}^{2}$ ) and energy $3 \mathrm{keV}$ (fluence $2 \times 10^{17} \mathrm{ion} / \mathrm{cm}^{2}$ ). These regimes will be shortly named as 1-16, 1-17 and 3-17 in further discussion.

\subsection{Mechanical Fatigue Tests}

Mechanical fatigue tests were carried out on the Bi 00-100 (by Bangalore Integrated System Solutions, Bangalore, India) servo-hydraulic free standing 2-column tension/compression testing machine with a frequency of $1 \mathrm{~Hz}$ (related with a heart pulse) and strain amplitude $\varepsilon$ of $10 \%, 20 \%$ or $40 \%$. The frequency and strain were selected from considerations of possible real exploitation 
conditions of the implants. The lowest value of strain was fixed at $10 \%$ due to residual deformations of the polymers, and the highest corresponds to the estimated maximal deformation of interphalangeal joint endoprosthesis [22]. The samples were remained preloaded to deformation of $2 \%, 5 \%$ or $10 \%$, respectively to prevent bending of the samples due to residual strain. The stiffness (stress, corresponding to strain amplitude) of the samples was decreased and after about 50,000 cycles ( $14 \mathrm{~h}$ of testing) stabilized, i.e., approached the asymptote. It was assumed that the sample reached steady working mode and could operate during a considerable number of cycles in this load range. After that, the surface of the sample was examined by optical and atomic force microscopy. The mechanical tests were repeated on several samples under the same loading conditions and the similar results were achieved.

\subsection{Microscopy}

An optical 3D-microscope (Hirox KH-7700, Tokyo, Japan) was used to obtain information on the microstructure of the surface at the scale of tens of microns. The detailed analysis of the surface was conducted by an atomic force microscope (Dimension Icon, Bruker, Billerica, MA, USA) in the semi-contact mode as well as in the nanomechanical mapping regime (PeakForce Capture, Bruker, Billerica, MA, USA). In the latter mode, together with the relief capturing, an indentation of the surface occurs. As a result, each point of the relief has its own force-displacement curve $F(z)$, which is expressed as: $F(z)=k d$, where $k$ and $d$ are the stiffness and deflection of the AFM-cantilever. The obtained curves $F(z)$ were processed by the Maugis-Dugdale model [23]. Two types of probes were used: (1) $k \sim 3-6 \mathrm{~N} / \mathrm{m}$, radius $R$ of the tip is $\sim 10 \mathrm{~nm}$; (2) $k=0.5 \mathrm{~N} / \mathrm{m}, R \sim 4 \mathrm{~nm}$. The stiffness was calibrated by the method of free thermal oscillations (built in the microscope software). The geometry of the probe tip was estimated by the blind estimation method [24] using the calibration grating of porous aluminum (PA01, manufactured by MikroMash, Tallinn, Estonia).

The surface structure of stretched materials is of particular interest. In this case, the samples that passed the fatigue tests were fixed in a miniature tensile device and stretched to the amplitude of previously applied fatigue load. After completion of the relaxation processes the surfaces were examined by optical and atomic force microscopy.

The cross-sections of the treated polyurethanes were studied to estimate the thickness of the hard modified layer. The PIII-treated surface was coated with the same polyurethane ( 1 mm thick). Some portion of the material was then removed from the side surface of the sample by the cryo-ultramicrotome (Leica UC7, Vienna, Austria) at $-100{ }^{\circ} \mathrm{C}$ using a diamond knife. By this way, the surface containing the cross-section of modified layer in the middle was prepared and its thickness was measured by the AFM [19].

\section{Results and Discussion}

Depending on the energy and fluence, the relief acquires a wrinkled structure and surface becomes harder. Detailed analysis of structural-mechanical properties of the treated surfaces (roughness, fractal and wave properties, elastic modulus) and the cross-sections of the modified layer are given in the work [19]. In particular, the elastic modulus of the surface, determined by the AFM nanoindentation, increases with the plasma energy and fluence and was $20 \mathrm{MPa}$ for the untreated PU, $125 \mathrm{MPa}$ (PIII 1-16), $254 \mathrm{MPa}(1-17)$ and $1900 \mathrm{MPa}(3-17)$.

The AFM images of untreated and treated materials are shown in Figure 1. The surface roughness rises with the treatment. After PIII 3-17 the surface has wrinkled structure. 

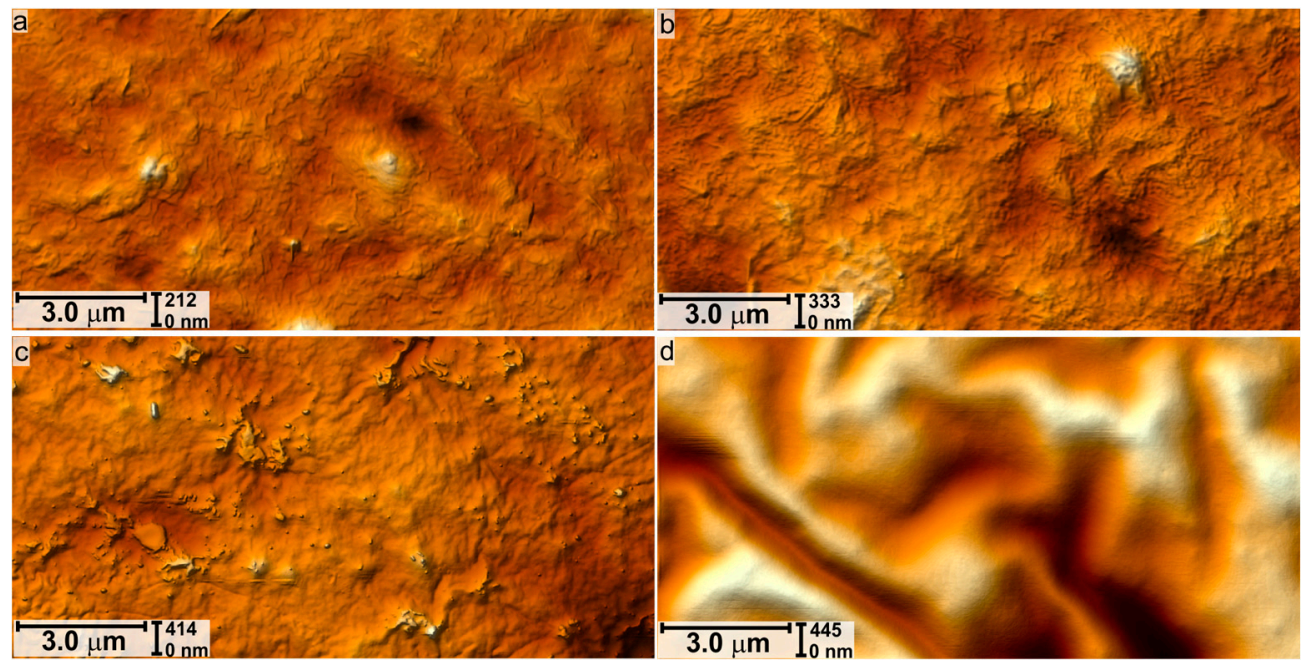

Figure 1. AFM images $15 \times 7.5 \mu \mathrm{m}^{2}$ of untreated (a) and treated with $1 \mathrm{keV}, 2 \times 10^{16} \mathrm{ion} / \mathrm{cm}^{2}$ (b); $1 \mathrm{keV}, 2 \times 10^{17} \mathrm{ion} / \mathrm{cm}^{2}(\mathbf{c}) ; 1 \mathrm{keV}, 3 \times 10^{17} \mathrm{ion} / \mathrm{cm}^{2}$ (d) surfaces.

As a result of ion implantation, a hard layer is formed on the surface of the material. Its thickness was estimated experimentally: 25, 30 and $50 \mathrm{~nm}$ [19].

The treated surfaces after fatigue loading are covered by cracks orthogonal to the strain direction and by folds (parallel to the loading) - a result of material compression. In the material subjected to PIII 3-17 these cracks and folds are clearly visible in the optical microscope (Figure 2). Hereinafter (Figure 2) the strain direction is vertical.

(a)

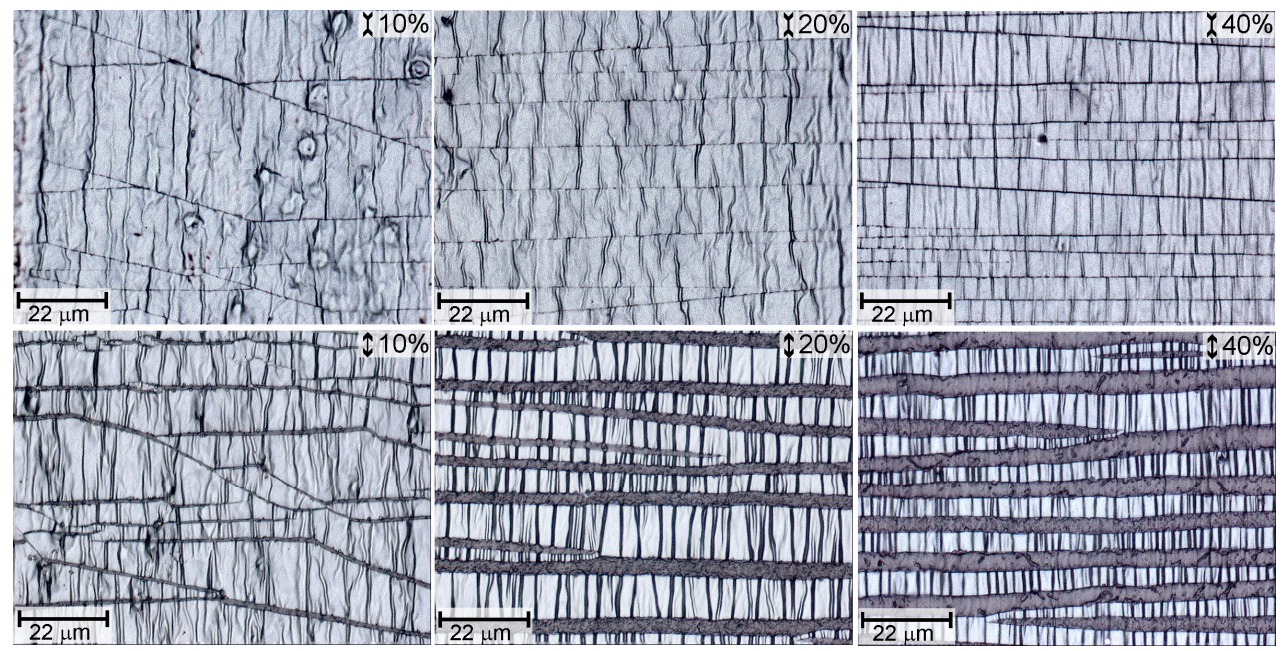

Figure 2. Optical images of PU after PIII 3-17 and fatigue loading ( $\varepsilon=10 \%, 20 \%, 40 \%)$ in the unloaded (a) and stretched (b) states. The strain direction is vertical.

Non-orthogonal cracks (Figure 2) are visible after $\varepsilon=10 \%$, this is due to bending/torsion of the samples caused by the residual deformation.

Let us investigate the damage of modified surface in greater detail. The surface after the 1-16 treatment and the fatigue loading $10 \%$, in the unloaded state covered by straight open cracks (Figure 3a) with a depth of 10-100 $\mathrm{nm}$ and a width of 50-700 $\mathrm{nm}$ (the average values are given below in Table 1). Such a spread is related to an inhomogeneous deformation at small $\varepsilon$. The profile of such crack is shown in Figure 3a. The edges of the cracks are always located at different heights relative to each other. The depth of the crack is measured from the lowest one edge. 

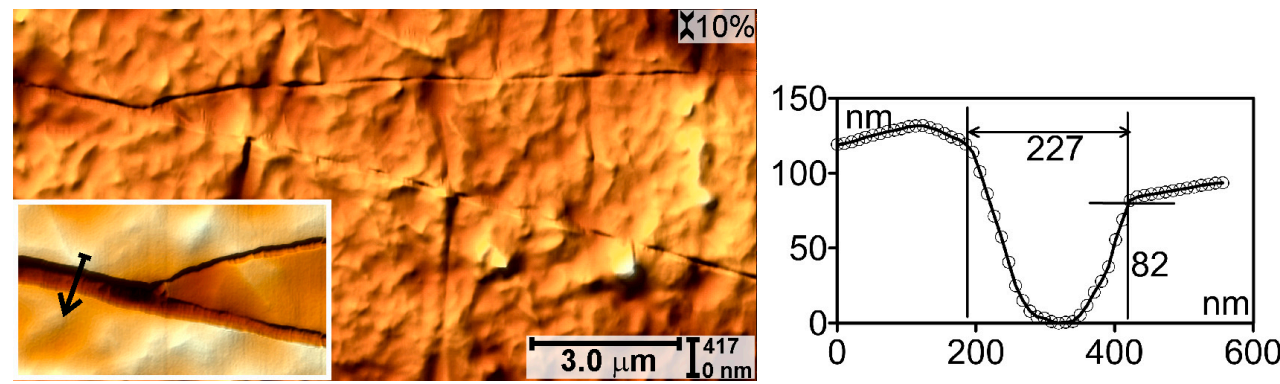

(a)
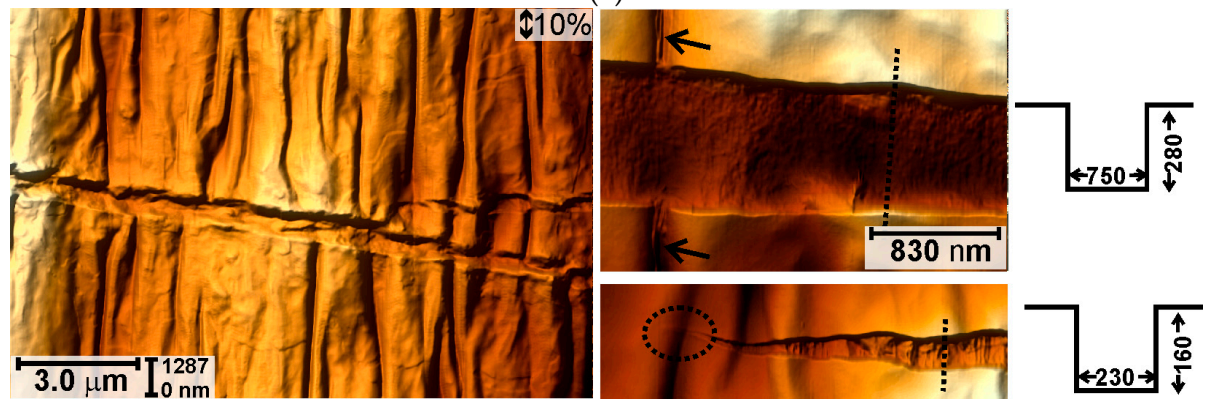

(b)

Figure 3. AFM images of PU after the PIII 1-16 and fatigue loading to $10 \%$ : open cracks are visible in the unloaded (a) and stretched (b) states. Longitudinal folds appear on the stretched surface. The width and depth (in $\mathrm{nm}$ ) of the cracks are indicated. The arrows in (b) indicate the bending of folds and the circle marks the crack tip stopped by the fold.

Apart from the cracks, the longitudinal folds appear on the surface after loading, which are the result of compression of the material in the transverse direction. In some cases, such folds break (shown by the arrows in Figure $3 b$ ) and bend inward. Note, that the folds stop the propagation of transverse cracks (marked by the circle in Figure $3 b$ ).

The depth of the cracks is more than order of magnitude greater the thickness of the modified surface layer. It means that cracks are generated on a hard surface and then propagate deep into the material.

With an increase of the fatigue deformation to $20 \%$ (Figure $4 a$ ), cracks with overlapping edges were observed on the 1-16 treated surface. In the stretched state some longitudinal folds break and bend inward. The map of the elastic modulus (Figure $4 \mathrm{~b}$ ) shows contrast between soft PU and hard coating. The hard edges of the bent folds destroy the polymer and squeeze it out to the surface (shown by the arrow in Figure 4 b).

During the fatigue loading, the hard crack edges cut soft polymer in the crack zone, which causes its partial detachment from the rest of the matrix and squeezing out of the crack edges (denoted by a rectangle in Figure 4 b).

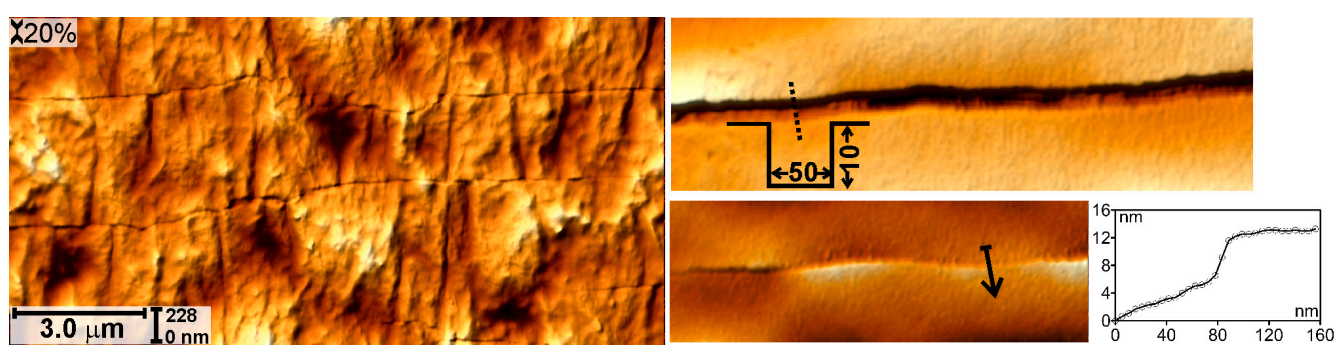

(a)

Figure 4. Cont. 


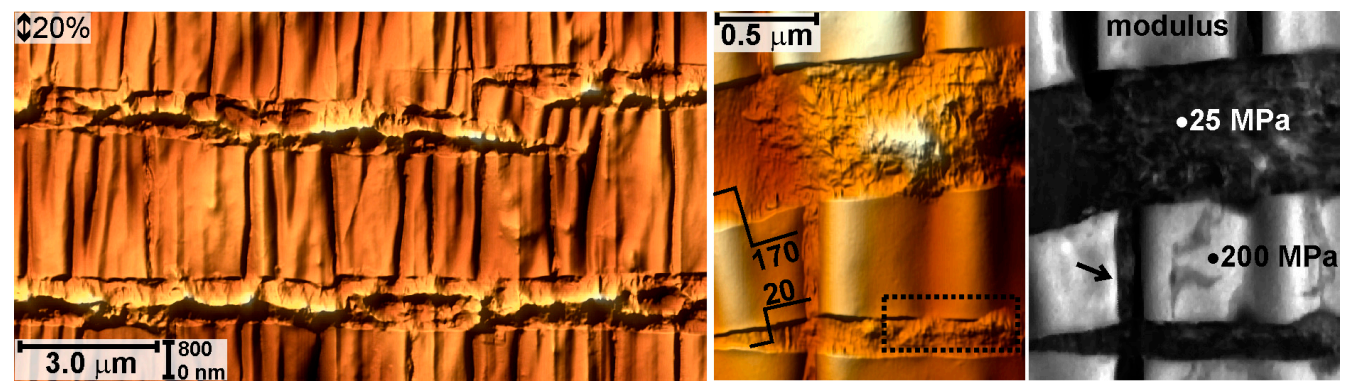

(b)

Figure 4. AFM images of PU after the PIII 1-16 and fatigue loading to $20 \%$ : open cracks in the unloaded (a) and stretched (b) states. Cracks with overlapping edges are also observed on the unloaded surface (shown by arrow in (a)). The height differences in the cracks are indicated (in $\mathrm{nm}$ ); arrow and rectangle in (b) indicate polymer squeezed from the cracks.

After higher strain, $\varepsilon=40 \%$, irregular cracks occur on the surface of the 1-16-treated material (Figure 5a). The propagation of these cracks is hampered by the longitudinal folds and surface irregularities. That the outer hard part of the modified layer is partially destroyed in plane: in the stretched state the damaged surface takes a step-like form (Figure $5 b$ ).

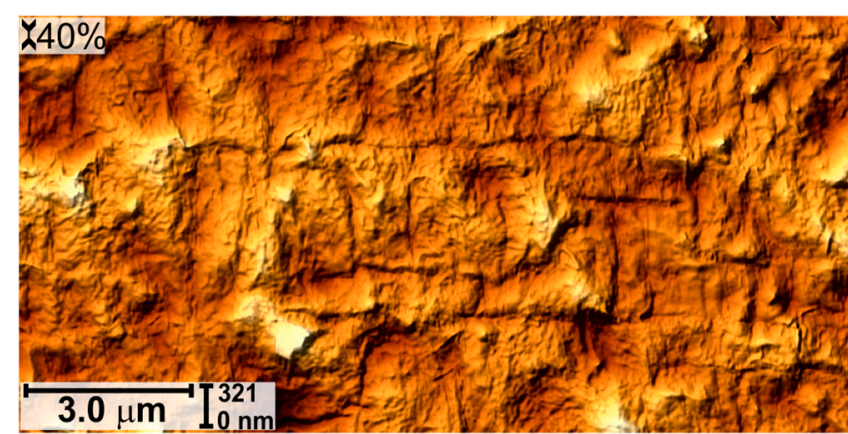

(a)

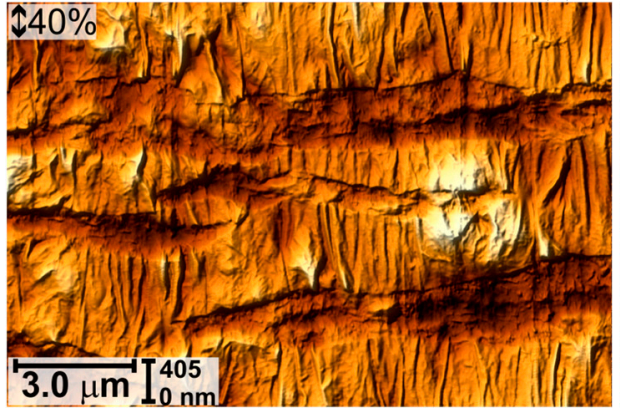

(b)

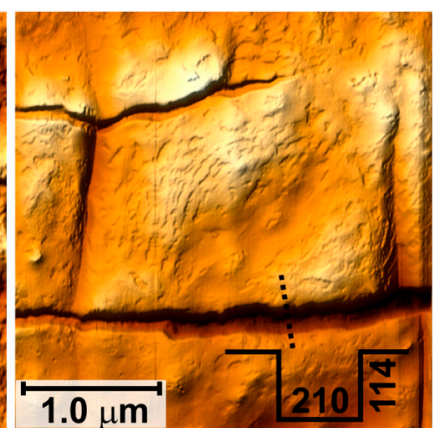

$1.0 \mu \mathrm{m}$

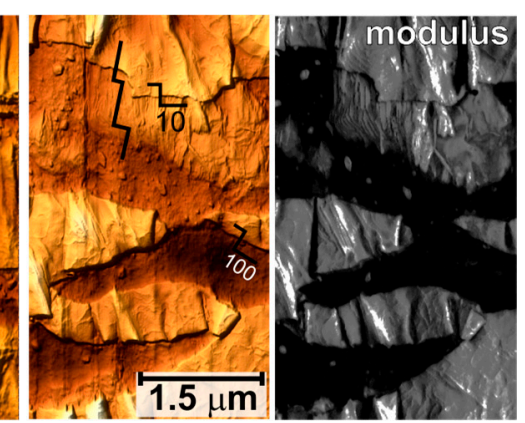

Figure 5. AFM images of PU after the PIII 1-16 and fatigue loading to $40 \%$ in the unloaded (a) and stretched (b) states. The stepped surface in (b) indicates the in plane fracture of the modified layer. The height of steps is shown (in $\mathrm{nm}$ ).

The surface of the material treated with higher fluence (PIII 1-17) after the fatigue tests is more uniform. The loading up to 10 and $20 \%$ causes only straight closed cracks with the edges bent inward (Figures 6a and 7a). The profile of one of these cracks is shown in the inset in Figure 7a. No open cracks were detected. After $\varepsilon=10 \%$ there are predominantly separate, short cracks (see the inset in Figure 6a), which are opened in stretched state (Figure 6b). 


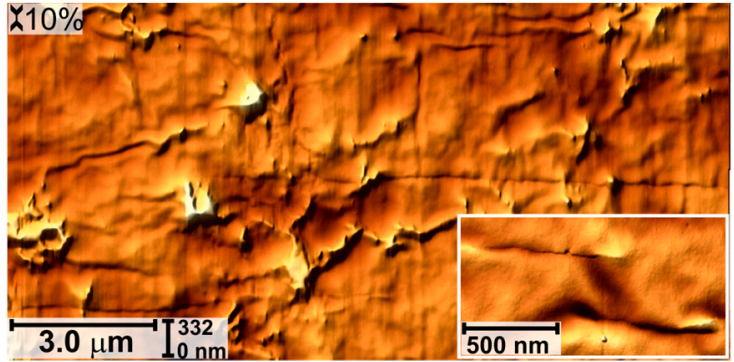

(a)

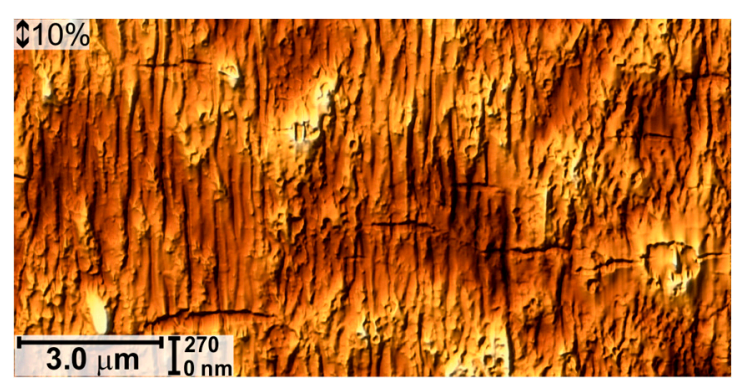

(b)

Figure 6. AFM images of PU after the PIII 1-17 and fatigue loading to $10 \%$ in the unloaded state (a) the closed cracks are visible, which are open in stretched state $(\mathbf{b})$.

Amplification of strain to $20 \%$ increases the length of the cracks. The surface inhomogeneities inhibit the development of cracks (enclosed in frames in Figure 7a). In the stretched state, as in the previous case (see Figure $4 \mathrm{~b}$ ), the longitudinal folds break, and the dissected by the crack edges polymer rises on the surface in the middle of the cracks (see Figure $7 b$ ).

A similar picture of the surface fracture is observed after $\varepsilon=40 \%$ (Figure 8). Figure 8 a shows the unloaded state: clots of the polymer squeezed from the cracks are marked by the frames and polymer squeezed out of the broken longitudinal folds is shown by the arrows. Note, that raw polymer in the open cracks in the stretched state (Figures $7 \mathrm{~b}$ and $8 \mathrm{~b}$ ) has an oriented structure along the axis of deformation.

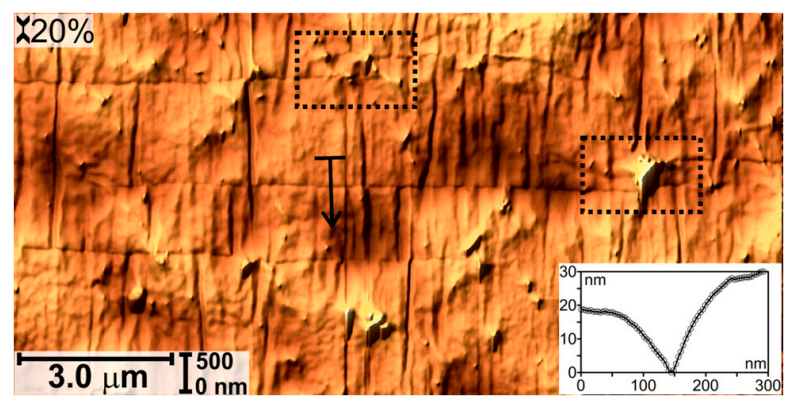

(a)

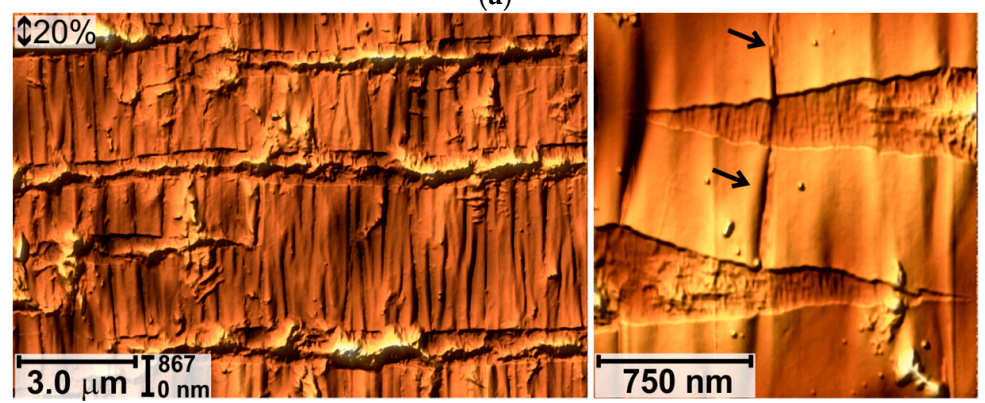

(b)

Figure 7. AFM images of PU after the PIII 1-17 and fatigue loading to $20 \%$ in the unloaded (a) and stretched (b) states. Surface inhomogeneities stop propagation of cracks (marked by box in (a)). Stiff edges of the broken layer dissect polymer in the cracks, clots of it are visible above the cracks (b). The broken longitudinal fold makred in (b) by arrows.

Increase of treatment energy results in the even more damaged surface. Closed cracks with overlapping edges, clots of polymer were observed after the PIII 3-17 and $\varepsilon=10 \%$. In the stretched state the width and depth of these cracks reach $1 \mu \mathrm{m}$ and $\sim 350 \mathrm{~nm}$, respectively. The surface of the polymer in the open cracks is quite rough; this is the result of its damage during fatigue deformation. 


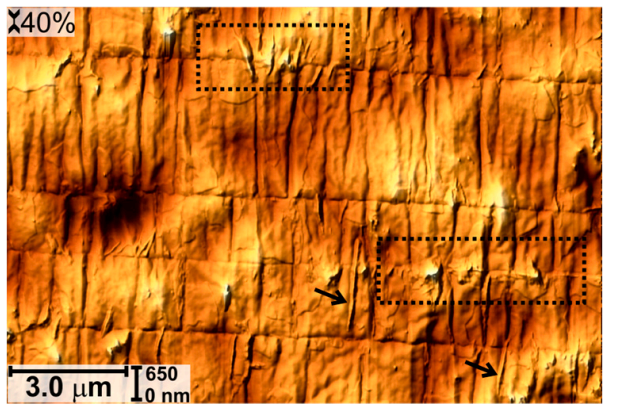

(a)

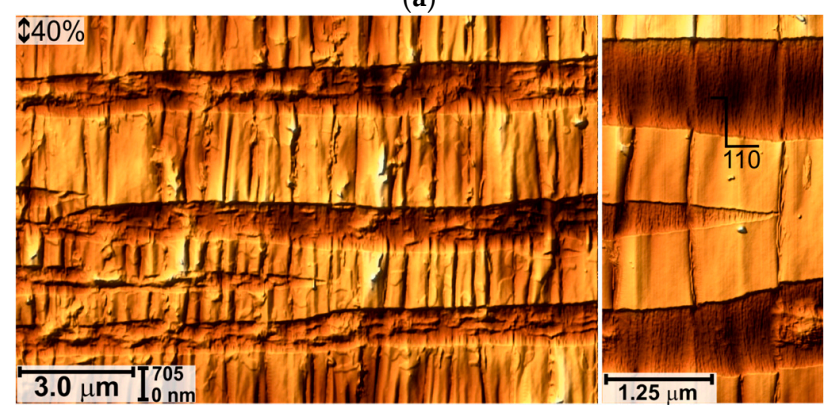

(b)

Figure 8. AFM images of PU after the PIII 1-17 and fatigue loading to $40 \%$ in the unloaded (a) and stretched (b) state. In (a) the polymer squeezed out from the cracks is marked by rectangles and arrows. In (b) the height of crack edge is shown (in $\mathrm{nm}$ ).

After $\varepsilon=40 \%$ open cracks (200-500 $\mathrm{nm}$ wide, $120-600 \mathrm{~nm}$ deep) appear on the unloaded material as well as longitudinal folds and fragments of the squeezed polymer (Figure 9a). The width of cracks on the stretched material is $\sim 3.0 \mu \mathrm{m}$ (Figure $9 \mathrm{~b}$ ). The surface is extremely heterogeneous, fragments of polymer and hard layer are visible in the cracks. Small cracks of submicron sizes are also observed on the tops of the longitudinal folds (indicated by the arrow in Figure 9b).

The morphology of the surfaces after fatigue loading is summarized in Table 1.
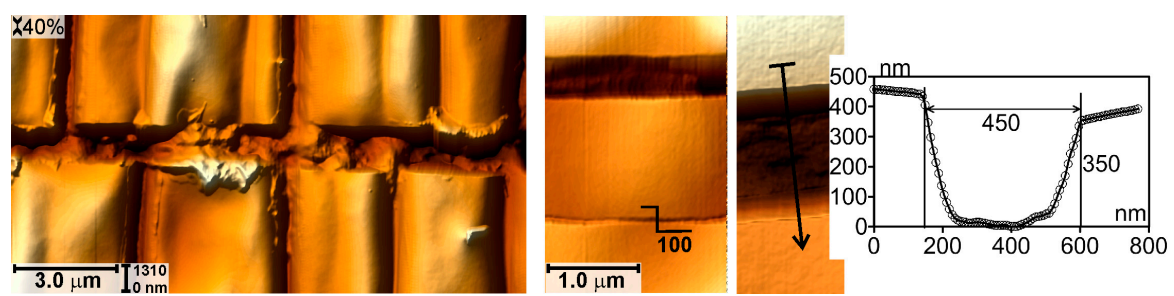

(a)

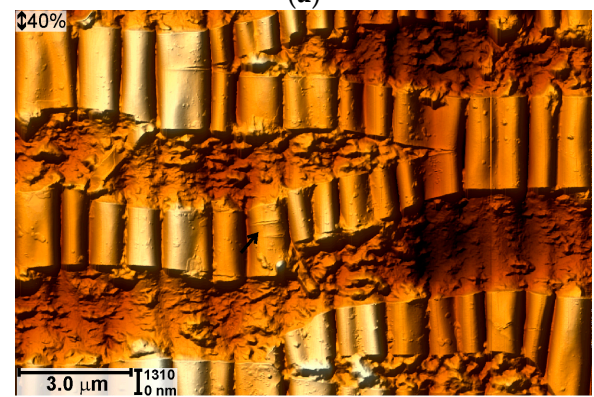

(b)

Figure 9. AFM images of PU after the PIII 3-17 and fatigue loading to $40 \%$ in the unloaded (a) and stretched (b) states. In (a) the height of crack step is shown (in $\mathrm{nm}$ ). Crack of submicron size appeared on the folded layer is marked in (b). 
Table 1. Surface morphology after the fatigue loading.

\begin{tabular}{|c|c|c|c|c|c|c|c|c|c|}
\hline \multirow{2}{*}{$\begin{array}{c}\text { Treatment Regime } \\
\text { Fatigue strain, } \%\end{array}$} & \multicolumn{3}{|c|}{$1 \mathrm{keV} 2 \times 10^{16}$ ions $/ \mathrm{cm}^{2}$} & \multicolumn{3}{|c|}{$1 \mathrm{keV} 2 \times 10^{17}$ ions $/ \mathrm{cm}^{2}$} & \multicolumn{3}{|c|}{$3 \mathrm{keV} 2 \times 10^{17}$ ions $/ \mathrm{cm}^{2}$} \\
\hline & 10 & 20 & 40 & 10 & 20 & 40 & 10 & 20 & 40 \\
\hline Open cracks & + & + & + & - & - & + & - & + & + \\
\hline Closed cracks & - & + & + & + & + & + & + & + & + \\
\hline Overlapping of crack edges & - & + & + & + & + & - & + & + & + \\
\hline Clots of matrix & - & + & + & - & + & + & + & + & + \\
\hline Fracture of folds & + & + & + & - & + & + & - & + & + \\
\hline $\begin{array}{l}\text { In plane fracture of the } \\
\text { coating }\end{array}$ & - & - & + & - & - & - & - & - & - \\
\hline Width of cracks, $\mu \mathrm{m}$ & 0.67 & 0.96 & 1.61 & 0.42 & 0.75 & 1.2 & 0.9 & 2.9 & 4.5 \\
\hline Depth of cracks, $\mu \mathrm{m}$ & 0.17 & 0.155 & 0.185 & 0.07 & 0.05 & 0.12 & 0.26 & 0.66 & 0.50 \\
\hline
\end{tabular}

Regardless the loading and treatment regimes, the fatigue loading damages not only on the treated surface layer, but affects the beneath polymer.

Judging by the width and depth of cracks, the most significant damage occurs in PUs treated with the lowest $\left(1 \mathrm{keV}, 2 \times 10^{16}\right.$ ions $\left./ \mathrm{cm}^{2}\right)$ and the highest $\left(3 \mathrm{keV}, 2 \times 10^{17}\right.$ ions $\left./ \mathrm{cm}^{2}\right)$ regimes. From the one hand, the observed fracture is related with the hardness of the layer, which is one (energy $1 \mathrm{keV}$ ) or two (energy $3 \mathrm{keV}$ ) orders of magnitude higher than the polymer. Another point is the peculiarities of the interphase between the stiff part of the modified layer and the bulk polymer. In the case of low energy and fluence (1-16), a hard layer is formed in the material without pronounced gradient of stiffness. The sharp transition from hard to soft materials reduces the compatibility of the modified layer and the substrate. This layer breaks in plane (Figure $5 b$ ).

In the case of highest treatment, hardening takes place almost to the entire depth of ion penetration in the material and the transition zone is also weak. In the intermediate treatment $\left(1 \mathrm{keV}, 2 \times 10^{17}\right.$ ions $\left./ \mathrm{cm}^{2}\right)$, ions can penetrate to the same maximal depth as in the case 1-16; although a higher fluence allows a smoother gradient from the bulk polymer to the treated surface.

The plasma treatment also affects the residual deformations of the modified surface: only closed cracks were observed after the 1-17 treatment at $\varepsilon \leq 20 \%$. In other cases, both open and closed cracks were detected. Moreover, the width of cracks in the stretched 1-17-treated PU was smaller in comparison with other regimes. This means, that in this coating the plastic contribution to the deformation is the weakest.

\section{Conclusions}

The effect of fatigue loading on the surface of polyurethane treated with plasma immersion ion implantation was investigated. It has been found that depending on the strain and treatment parameters different types of damage occur on the surface of the materials after loading (see Table 1): open and closed cracks transverse to the strain, longitudinal folds that can break and bend inward. During the mechanical loading, the edges of the cracks cut the polymer, clots of the detached polymer bugle and squeeze to the surface.

The lower is the strain amplitude; the less is the resulting damage. However, even at small stain of $10 \%$ the depth of the cracks is an order of magnitude greater than the thickness of the modified layer. The greater amplitudes lead to even more damages, like detachment of polymer from the cracks.

From the viewpoint of treatment the character of the damage is associated with the transition region between the hard layer, which is formed near the surface, and the bulk polymer. Increase in the ion energy and reduction of the fluence can facilitate the development of coatings with higher fracture resistance. Another possible direction is the design of discontinuous cluster-like coatings [7], which could be more stable to the external loading.

The usage of these materials in the present state in deformable biomedical products can lead to damage of the implant and eventually of body tissues.

Acknowledgments: The work is supported by Russian Science Foundation, Grant No. 17-79-20042. 
Author Contributions: Ilya A. Morozov designed and performed AFM experiments and wrote the paper; Alexander S. Mamaev designed and performed plasma treatment; Mikhail V. Bannikov designed and performed fatigue tests; Anton Yu. Beliaev analysed the data; Irina V. Osorgina prepared the polymers.

Conflicts of Interest: The authors declare no conflict of interest.

\section{References}

1. Xi, Y.; Liu, D.; Han, D. Improvement of corrosion and wear resistances of AISI 420 martensitic stainless steel using plasma nitriding at low temperature. Surf. Coat. Technol. 2008, 202, 2577-2583. [CrossRef]

2. Jiang, L.; Tang, Z.; Clinton, R.M.; Breedveld, V.; Hess, D.W. Two-step process to create "roll-off" superamphiphobic paper surfaces. ACS Appl. Mater. Interfaces 2017, 9, 9195-9203. [CrossRef] [PubMed]

3. Cheruthazhekatt, S.; Černák, M.; Slavíček, P.; Havel, J. Gas plasmas and plasma modified materials in medicine. J. Appl. Biomed. 2010, 8, 55-66. [CrossRef]

4. Hauert, R.; Thorwarth, K.; Thorwarth, G. An overview on diamond-like carbon coatings in medical applications. Surf. Coat. Technol. 2013, 233, 119-130. [CrossRef]

5. Stüber, M.; Niederberger, L.; Danneil, F.; Leiste, H.; Ulrich, S.; Welle, A.; Marin, M.; Fischer, H. Surface topography, surface energy and wettability of magnetron-sputtered amorphous carbon (a-C) films and their relevance for platelet adhesion. Adv. Eng. Mater. 2007, 10, 1114-1122. [CrossRef]

6. Wang, J.; Yang, P.; Sun, H.; Chen, J.Y.; Leng, Y.X.; Wan, G.J.; Huang, N. Surface modification of medical polyurethane by acetylene plasma immersion ion implantation. In Proceedings of the 30th International Conference on Plasma Science, Jeju, Korea, 2-5 June 2003; p. 282.

7. Alekhin, A.P.; Boleiko, G.M.; Gudkova, S.A.; Markeev, A.M.; Sigarev, A.A.; Toknova, V.F.; Kirilenko, A.G.; Lapshin, R.V.; Kozlov, E.N.; Tetyukhin, D.V. Synthesis of biocompatible surfaces by nanotechnology methods. Nanotechnol. Russia 2010, 5, 696-708. [CrossRef]

8. Kosobrodova, E.A.; Kondyurin, A.V.; Fisher, K.; Moeller, W.; McKenzie, D.R.; Bilek, M.M.M. Free radical kinetics in a plasma immersion ion implanted polystyrene: Theory and experiment. Nucl. Instrum. Methods B 2012, 280, 26-35. [CrossRef]

9. Melnig, V.; Apetroaei, N.; Dumitrascu, N.; Suzuki, Y.; Tura, V. Improvement of polyurethane surface biocompatibility by plasma and ion beam techniques. J. Optoelectron. Adv. Mater. 2005, 7, 2521-2528.

10. Cao, H.; Liu, X.; Meng, F.; Chu, P.K. Biological actions of silver nanoparticles embedded in titanium controlled by micro-galvanic effects. Biomaterials 2011, 32, 693-705. [CrossRef] [PubMed]

11. Zhang, W.; Zhang, Y.; Ji, J.; Yan, Q.; Huang, A.; Chu, P.K. Antimicrobial polyethylene with controlled copper release. J. Biomed. Mater. Res. A 2007, 83A, 838-844. [CrossRef] [PubMed]

12. Jiří, K.; Kahoun, D.; Štěrba, J.; Langhansová, H.; Lieskovská, J.; Fojtíková, P.; Hanuš, J.; Kousal, J.; Kylián, O.; Straňák, V. Plasma polymerized C:H:N:O thin films for controlled release of antibiotic substances. Plasma Process. Polym. 2017, e1700160. [CrossRef]

13. Bonaccurso, E.; Cappella, B.; Graf, K. Local mechanical properties of plasma treated polystyrene surfaces. J. Phys. Chem. B 2006, 110, 17918-17924. [CrossRef] [PubMed]

14. Kondyurina, I.; Nechitailo, G.S.; Svistkov, A.L.; Kondyurin, A.; Bilek, M. Urinary catheter with polyurethane coating modified by ion implantation. Nucl. Instrum. Methods B 2015, 342, 39-46. [CrossRef]

15. Tsougeni, K.; Tserepi, A.; Boulousis, G.; Constantoudis, V.; Gogolides, E. Control of nanotexture and wetting properties of polydimethylsiloxane from very hydrophobic to super-hydrophobic by plasma processing. Plasma Process. Polym. 2007, 4, 398-405. [CrossRef]

16. Perera-Costa, D.; Bruque, J.M.; González-Martín, M.L.; Gómez-García, A.C.; Vadillo-Rodríguez, V. Studying the influence of surface topography on bacterial adhesion using spatially organized microtopographic surface patterns. Langmuir 2014, 30, 4633-4641. [CrossRef] [PubMed]

17. Morozov, I.A.; Mamaev, A.S.; Osorgina, I.V.; Lemkina, L.M.; Korobov, V.P.; Belyaev, A.Y.; Porozova, S.E.; Sherban, M.G. Structural-mechanical and antibacterial properties of a soft elastic polyurethane surface after plasma immersion $\mathrm{N}_{2}{ }^{+}$implantation. Mater. Sci. Eng. C 2016, 62, 242-248. [CrossRef] [PubMed]

18. Bowden, N.; Brittain, S.; Evans, A.G.; Hutchinson, J.W.; Whitesides, G.M. Spontaneous formation of ordered structures in thin films of metals supported on an elastomeric polymer. Nature 1998, 393, 146-149. [CrossRef] 
19. Morozov, I.A.; Mamaev, A.S.; Osorgina, I.V.; Beliaev, A.Y.; Izumov, R.I.; Oschepkova, T.E. Soft polyurethanes treated by plasma immersion ion implantation: Structural-mechanical properties of surface modified layer. J. Appl. Polym. Sci. 2018, 135, 45983. [CrossRef]

20. Panchuk, D.A.; Sadakbaeva, Z.K.; Bagrov, D.V.; Kechek'yan, A.S.; Bol'shakova, A.V.; Abramchuk, S.S.; Yarysheva, L.M.; Volynskii, A.L.; Bakeev, N.F. Specific features of surface structuring during deformation of plasma-treated polymer films. Polym. Sci. A 2010, 52, 794-800. [CrossRef]

21. Gavrilov, N.V.; Mamaev, A.S. Low-temperature nitriding of titanium in low-energy electron beam excited plasma. Tech. Phys. Lett. 2009, 35, 713-716. [CrossRef]

22. Beliaev, A.; Svistkov, A.; Iziumov, R.; Osorgina, I.; Kondyurin, A.; Bilek, M.; McKenzie, D. Modelling of the mechanical behavior of a polyurethane finger interphalangeal joint endoprosthesis after surface modification by ion implantation. IOP Conf. Ser. Mater. Sci. Eng. 2016, 123. [CrossRef]

23. Piétrement, O.; Troyon, M. General equations describing elastic indentation depth and normal contact stiffness versus load. J. Colloid Interfaces Sci. 2000, 226, 166-171. [CrossRef] [PubMed]

24. Villarrubia, J.S. Algorithms for scanned probe microscope image simulation, surface reconstruction, and tip estimation. J. Res. Natl. Inst. Stand Technol. 1997, 102, 425-454. [CrossRef] [PubMed]

(C) 2018 by the authors. Licensee MDPI, Basel, Switzerland. This article is an open access article distributed under the terms and conditions of the Creative Commons Attribution (CC BY) license (http:// creativecommons.org/licenses/by/4.0/). 